\title{
A INFLUÊNCIA DA ERGONOMIA EM MELHORIAS PRODUTIVAS UTILIZANDO A EQUAÇÃO NIOSH
}

\section{THE INFLUENCE OF ERGONOMICS IN PRODUCTIVE IMPROVEMENTS USING NIOSH EQUATION}

\author{
Emerson da Silva Moreira ${ }^{1}$, Luiz Eduardo Nicolini do Patrocínio Nunes ${ }^{2}$ \\ ${ }^{1}$ Universidade de Taubaté - UNITAU - Taubaté - SP - Brasil \\ emoreira2002@ hotmail.com \\ ${ }^{2}$ Universidade de Taubaté - UNITAU - Taubaté - SP - Brasil \\ lgpnunes@outlook.com
}

\begin{abstract}
Resumo
As posturas são fatores que influenciam a estrutura óssea das pessoas, este estudo mostra a necessidade de uma boa postura, para o desenvolvimento de uma atividade vêm desde a antiguidade e chega aos dias atuais, exemplos de melhorias referenciado a Bernardino Ramazzini, sendo o primeiro a escrever sobre doenças ocupacionais, suas conseqüências para o organismo, mostrando ferramentas adequadas para cada atividade, gerando ganhos produtivos, com menores impactos para a saúde, segurança, para o corpo humano.

A estrutura da coluna vertebral e o impacto quando levantamos ou movimentamos objetos, peso acima de $4 \mathrm{~kg}$ já é considerado elevado para a manipulação, podendo causar danos ao tecido muscular, apresenta uma ferramenta identificada como Equação de Levantamento Revisado do National Institute for Occupational Safety and Health (NIOSH), criado na década de 80 e revisado em 90, tendo como finalidade identificar critérios epidemiológicos, psicológicos, biomecânicos e fisiológico e encontrar condições para identificar o Limite de Peso Recomendável (LPR) para a atividade e assim identificar um Índice de Levantamento (IL) que é encontrado com a divisão da carga pelo LPR, chegando a um valor que define o risco de lesão ao trabalhador. Apresenta uma aplicação real, a atividade inicial, seus riscos, melhorias e o aumento no limite do peso a ser movimentado e a redução do risco de lesão por parte do trabalhador. Este trabalho mostra que em uma boa analise ergonomica podemos movimentar cargas mais pesadas e com menos riscos, ampliando a produtividade, reduzindo o absentismo e afastamentos decorrentes deste motivo.
\end{abstract}

Palavras-chave: ergonomia; equação de levantamento revisado niosh; doenças ocupacionais

\section{Introdução}

O Brasil tem uma das maiores incidências de acidentes do mundo, segundo dados divulgados pelo Anuário Brasileiro de Acidentes, divulgado para o período de 2013, onde ocorreram neste ano 711.164 acidentes, registrados pela previdência Social, ou seja, apenas aqueles acidentes relacionados ao trabalho ocorridos com pessoas devidamente registrado, foi identificado 
um grande numero de acidente, sendo este apresentado da seguinte forma: Acidente com vitima ocorreram aproximadamente a cada 1,50 minutos (um minuto e meio) e um acidente com morte a cada 3 horas (Proteção, 2013). Visando reduzir este índice, a portaria 3.214, de 8 de junho de 1978, aprovou as Normas Regulamentadoras ao trabalho, (NR) do Capitulo V, Título II, da Consolidação das Leis do Trabalho (CLT), onde aborda os itens referentes à Segurança e Medicina do Trabalho, atualmente encontra-se em 36 NR's, servindo como referencia para as empresas procurarem realizar melhorias mitigando e, se possível, eliminar possíveis causas que venham a propiciar acidentes nas empresas.

O desenvolvimento da humanidade sempre esteve paralelo a melhorias de produtos e processos, visando reduzir os movimentos do trabalhador e obter ganhos produtivos. Cada vez mais é verificado a importância e os impactos das atividades para o corpo humano.

Este trabalho vai abordar a (NR 17 - Ergonomia), procurando abordar fatores ergonômicos e, apresentar uma ferramenta para abordar a movimentação de levantamento de cargas, chamada Equação de Levantamento Revisado do NIOSH (National Institute for Occupátional Safety and Helth), visando reduzir a movimentação e atividades que requerem esforços excessivosque venham a gerar consequencias temporárias ou até mesmo permanentes ao trabalhador. Esta ferramenta avalia levantamentos de carga, demanda física das atividades de levantamento manual de cargas e identificar o risco de lesões por sobrecarga, determinando o Limite de Peso Recomendada (LPR) e o Índice de Levantamento (IL) que apresentam o peso Maximo a ser manuseado pelo trabalhador e o índice de risco que a atividade pode proporcionar riscos para a coluna do operador, com a utilização desta equação pode-se identificar e reduzir os possíveis afastamentos causados por este motivo. Concluindo, será demonstrado uma situação, onde foi analisado a situação atual de trabalho, através de análises foi apresentado sugestões para adequação do posto de trabalho, melhorias ergonômicas adaptadas a situação do trabalhador, propiciando uma baixa condição de lesão para a coluna.

\section{Referencial Teórico}

Os primeiros estudos referentes a ergonomia foram realizados por Xenofonte, 427 a 355 A.C. e serviram de base para a divisão dos trabalhos, cada trabalhador efetuou apenas uma operação para a confecção de coturnos para a armada grega (SILVA; PASCHOARELLI , 2010). 
No século XV, Leonardo da Vinci desenha o Homem Vitruviano, onde apresenta uma figura masculina desnuda em duas posições sobreposta, sendo este o marco da antropometria e da biomecânica. (PAULA, et. al, 2010).

No século XVII, Bernardino Ramazzini, médico italiano, foi um dos primeiros a descrever doenças e lesões provocadas por atividades de trabalho, onde relata 54 (Cinquenta e quatro doenças ocupacionais) relacionadas as atividades e as condições de trabalho, onde o trabalhador é submetido, sendo estas as mais diversas atividades, explicando a relação entre trabalho/ambiente/doença. Tendo este estudo contribuído com as mais diversas áreas da medicina, onde podemos citar: a Oncologia, a Oftalmologia, a Pneumologia, a Ortopedia, entorno de 50\% das dermatoses ocupacionais reconhecidas, também foram identificadas por Ramazzini, porém teve seu trabalho censurado no momento que foi nos locais de trabalho de seus pacientes identificar as reais causas de suas doenças (Ramazzini, 2016).

Nas primeiras décadas do século XX, Lilian e seu marido Frank Bunker Gilbreth apresentaram sugestões para melhorar condições ergonômicas, padronizar o trabalho, estudos e movimentos. Seus projetos são utilizados inclusive fora da indústria, como nos nossos lares, podemos citar: o pedal para abrir latas de lixo, o suporte para porta ovos e a mangueira para descarga de águas residuais das máquinas de lavar (PAULA, et al, 2010).

Conforme Lida (2005), Frederick Wislow Taylor (1856 a 1915), considerava que todo o trabalho poderia ser cientificamente estabelecido, com tempos de trabalhos pré determinados, uma divisão de trabalho, ferramentas adequadas e responsabilidades na execução da atividade produtiva de forma clara.

O Taylorismo pode ser considerado negativo para alguns, sendo referência para trabalho duro e desumanizador, porém trouxe muitas inovações tais como:

- Trabalho Padronizado: Melhora e facilita o modo de efetivar o trabalho;

- $\quad$ Tempo de Ciclo Reduzido: Tempo que um determinado processo leva;

- $\quad$ Estudo de Tempo e Movimento: Desempenho de trabalho padronizado;

- Medição e Analise para Melhoria: Identificar, atuar e obter melhorias continuas.

Toledo (2007) exemplifica os conhecimentos científicos de Taylor aplicados na Bethlehem Steel Works. O resultado destes estudos identifica que um homem poderia manipular em média uma pá carregada com 9,75 Kg. Foi disponibilizada pás de acordo com o material a ser 
descarregado. Depois de 3 (três) anos este trabalho era realizado por 140 homens, diferente dos 400 a 600 homens anteriores.

As idéias de Taylor, difundiram-se nos Estados Unidos, na década de 1920, os seus estudos já estavam difundidos em todos os cursos relativos às áreas produtivas, criando condições favoráveis a estudos de cronometragem e melhorias ergonômicas, contribuindo para a predominância da indústria norte americana (TOLEDO, 2007).

As idéias do Taylorismo não surgiram de um escritório ou de um ilusionista, mas dentro das fabricas realizado através de observações empíricas do trabalho baseado em conhecimentos científicos, relacionados com a fisiologia do trabalho (LIDA, 2005).

Sabemos, que a baixa produtividade não esta ligada a vadiagem dos trabalhadores e os acidentes de trabalho a negligência, como atribuía Taylor. Muitos dos fatores ligados a projeto de máquinas e equipamentos, ambiente de trabalho, ambiente físico, além dos acidentes não acontecem de forma simples, mas devido a diversos fatores pré-existentes (LIDA, 2005).

\subsection{Definições Referentes a Ergonomia}

O Polonês W. Jastrzebowski utilizou em 1857, pela $1^{0}$ vez o sinônimo ergonomia, onde publicou um artigo intitulado "Ensaio da ergonomia ou ciência do trabalho baseado nas leis objetivas da ciência da natureza" (NETO, 2010). A ergonomia deriva das palavras gregas, ergo, (trabalho) e nomos (regra), já nos Estados Unidos também é utilizado o termo human factors (fatores humanos) (DUL; WENERMEEESTER, 2014).

A ergonomia tem como objetivo a melhoria do desempenho do sistema produtivo, focando na redução da fadiga, estress, erros e acidente, proporcionando uma maior sensação de segurança, satisfação e saúde em sua atividade de trabalho (LIDA, 2005).

Trabalho físico pesado, posturas incorretas, pouco treinamento ou inadequado, trabalho noturno, repetitivo, excessivo, mobiliário mal projetado, ambiente de trabalho desconfortável (seco, frio, quente, pouco iluminado, barulhento, apertado), dentre outros são fatores que influenciam riscos ergonômicos (NETO, 2010).

A analise ergonômica é condição obrigatória, porém por falta de uma fiscalização efetiva por parte do Ministério do Trabalho, um grande numero de trabalhadores acaba adoecendo, humilhados, sofrendo descaso e como não se bastasse as lesões físicas, esta situação pode gerar efeitos emocionais que são lentamente agredidos, causando feridas silenciosas, dificultando e muitas vezes tornando a sua cura quase impossível. 


\subsection{Objetivos da Ergonomia}

Para Machado (2013), vários são os objetivos da ergonomia, onde erg. (trabalho), ou seja a ergonomia não é um fim, mas um meio, que deve ser visto, para o bem estar do trabalhador, desta forma, vários são os objetivos da ergonomia, ao qual podemos destacar:

- $\quad$ Redução nos Índices de Acidentes;

- $\quad$ Sensível redução dos Custo referente a incapacidade dos trabalhadores;

- Melhoria nos Níveis de Produção;

- $\quad$ Melhoria na Qualidade do Trabalho;

- $\quad$ Redução do Absenteísmo;

- $\quad$ Cumprimento das Normas Regulamentadoras;

- $\quad$ Redução de Perdas de Matéria-Prima.

A ergonomia pode ser um fator principal para a solução de inúmeros problemas, como: sociais com a saúde, relação segurança, conforto no comprimento das tarefas, além da eficiência no trabalho. Muitos acidentes ocorrem quando o funcionário tem como referencia o relacionamento inadequado entre os operadores, seus equipamentos e suas tarefas, desta forma podemos perceber um caráter preventivo e corretivo da ergonomia. Ainda segundo Machado (2013), existem algumas vantagens ao se investir em ergonomia, em especial nos programas relacionados à ergonomia:

Para os Funcionários: Redução no desconforto, físico e da fadiga, reduzindo a irritabilidade do trabalhador; Reduzindo gastos energéticos, proporcionado uma redução do estresse ocupacional; Maior equilíbrio emocional; Redução de doenças; Melhor qualidade de vida e em conseqüência uma ampliação na eficiência do trabalho.

Para as Empresas: Redução nos gastos com assistência médica; Diminuição de absenteísmo e acidentes; Maior proteção legal contra possíveis ações judiciais, Melhoria na qualidade e produtividade; Melhora no ambiente do trabalho, propiciando uma boa imagem da empresa.

Para Lida (2005), A ergonomia centra-se na interação do ser humano com formas de trabalho e em diversos fatores que produzem uma influencia sobre essas interações, propiciando 
eficiência, reduzindo a fadiga, stress, erros e acidentes, segurança, satisfação e saúde aos trabalhadores, sendo apontados quatro objetivos principais:

Saúde: É mantida quando a exigência da atividade e do seu ambiente não ultrapasse as limitações energéticas e cognitivas, evitando situações de stress, riscos de acidentes e doenças ocupacionais;

Segurança: É obtida através de projetos bem elaborados dos locais de trabalho, ambiente e organização, que atendam as capacidades e limitações do trabalhador.

Satisfação: É o resultado do atendimento das necessidades e as expectativas do trabalhador, porém, pode variar conforme a cultura e diferenças individuais, necessidades e expectativas de cada um. Trabalhadores satisfeitos provocam um comportamento mais seguro, alem de serem mais produtivos que aqueles insatisfeitos;

Eficiência: É a conseqüência de um bom planejamento e organização do trabalho, proporcionando saúde, segurança e satisfação ao trabalhador, este item deve ser colocado dentro de certos limites, pois pode prejudicar a garantia dos três objetivos iniciais, já que o aumento indiscriminado da eficiência pode implicar em prejuízos a saúde e segurança do trabalhador.

\subsection{Informações Estatísticas}

A segurança no trabalho no Brasil é um ponto onde devemos nos atentar, pois no período de 2011, ocorreu a cada 3 horas 1 (uma) morte motivada por riscos decorrentes dos fatores ambientais do trabalho e proximo de 81 acidentes e doenças do trabalho reconhecidas a cada hora na jornada diária, neste período foi relatado em média cerca de 49 trabalhadores/dia que não retornam ao trabalho devido à invalidez ou morte. (BRASIL, Previdência, 2016)

A dor na região lombar é um dos principais motivos de afastamento por atividades profissionais em longos períodos (acima de 15 dias), é a segunda causa de afastamento para períodos curtos. Durante a vida, aproximadamente $80 \%$ das pessoas apresentam em algum tipo de dor lombar provocados por atividades de levantamento manual de cargas, esta no topo do ranking dos problemas de saúde gerados no emprego países industrializados, contribuindo com cerda de $30 \%$ de todos os afastamentos do trabalho por doenças e representa $50 \%$ do total de custos diretos relacionados a esses afastamentos. Aproximadamente a metade dessas pessoas apresenta dor irradiada para os membros inferiores e cerca de 5\% dores ciáticas (TEIXEIRA, 2011).

A movimentação e levantamento de cargas são responsáveis por grande parte das lesões musculares entre trabalhadores. Aproximadamente $60 \%$ dos problemas musculares são referentes a 
levantamento de cargas e $20 \%$ a atividade de puxar ou empurrar (DUL; WENERMEEESTER, 2014).

A coluna vertebral possui uma estrutura que serve de sustentação para o corpo humano, permitindo grande movimentação e está sujeito a lesões provocadas por agentes que venham a causar incapacidade temporária ou permanente. A estrutura anatômica da coluna, normalmente consiste em 33 vértebras, sendo dividida da seguinte forma: 7 Cervical, 12 Torácicas, 5 Lombares, 5 Sacrais e 4 Coccígeneas. Nos primeiros 24 ossos vertebrais são separados por discos intervertebrais fibrocartilaginosos, que servem como um amortecedor, os ossos do sacro e cóccix estão fundidos entre si. Segundo (Wirhed, 1986), o levantamento de objetos pesados provoca uma pressão elevada no disco pulposo, podendo romper o anel fibroso que serve como um amortecedor para as vértebras da coluna cervical.

Para levantar um objeto devemos posicionar de forma que o braço externo da alavanca seja o menor possível. A figura abaixo demonstra o efeito de uma postura para levantar uma carga, onde o troco $(40 \mathrm{Kg})+$ a carga $(10 \mathrm{Kg})$, equivalem a $500 \mathrm{~N}$. a musculatura dorsal, estando na posição correta (a), atua aproximadamente $5 \mathrm{~cm}$ da coluna vertebral L3. A alavanca externa corresponderá a $20 \mathrm{~cm}$, contra $30 \mathrm{~cm}$ na posição erradas (b).

Figura 1: Momento das forças posição correta

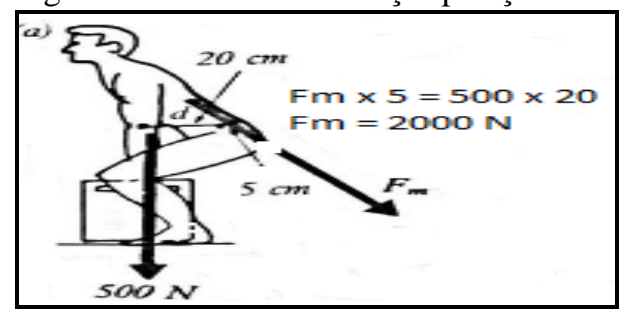

Fonte: Wirher, 1986
Figura 2: Momento das forças posição incorreta

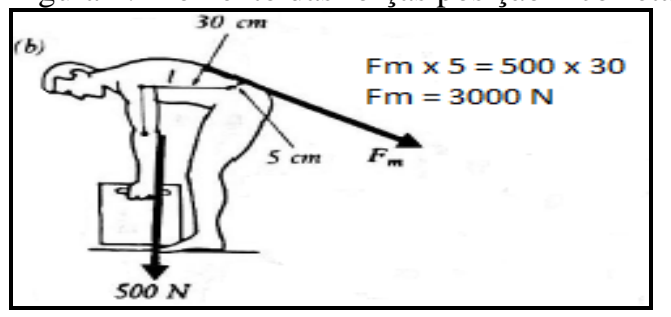

Fonte: Wirher, 1986

Quando levantamos uma carga de $10 \mathrm{~kg}$, sentado, a pressão que os músculos exercem sobre o disco intervertebral é maior, pois a distancia da alavanca do braço de apoio fica a $40 \mathrm{~cm}$ longe da coluna cervical, conforme apresentado na figura abaixo. $\mathrm{O}$ efeito compressor da musculatura dorsal pode reduzir em aproximadamente $40 \%$ a pressão sobre os discos intervertebrais.

Figura 3: Momento das forças sentado

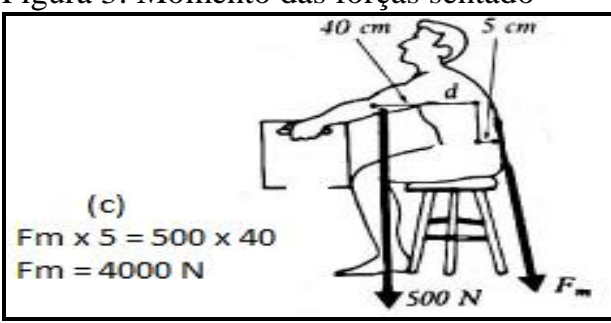

Figura 4: Compressão abdominal

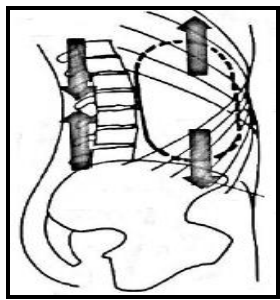


Além da necessidade da musculatura abdominal fortalecida, também existe a obrigação de músculos fortes nos membros inferiores, para que possam suspender e suportar pesos na posição correta, ou seja com os joelhos flexionados. Quando dividimos o peso de uma carga de forma simétrica, carregando com as duas mãos, esta carga será significativamente menor do que se for levantada com apenas uma mão.

A figura abaixo demonstra esta diferença, onde, em um levantamento simétrico o corpo pesa $40 \mathrm{Kg}$ acima da vértebra L3. A sobrecarga é de $30 \mathrm{Kg}$, sendo este dividido em dois totalizando 15 Kg para cada braço da alavanca dos músculos do dorso, a flexão lateral é de $5 \mathrm{~cm}$.

No Levantamento assimétrico uma carga de $30 \mathrm{Kg}$ é levantada por apenas uma das mãos, assim o centro de gravidade do corpo é alterado, nesta situação podemos atribuir $10 \mathrm{~cm}$ ao lado da L3, os músculos do dorso precisam estar contraídos para suportar esta carga que é maior em relação a postura simétrica.

Figura 5: Levantamento Simétrico de Carga

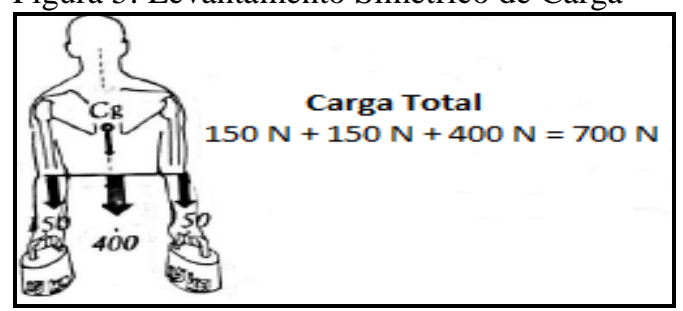

Fonte: Winher, 1986
Figura 6: Levantamento Assimétrico de Carga

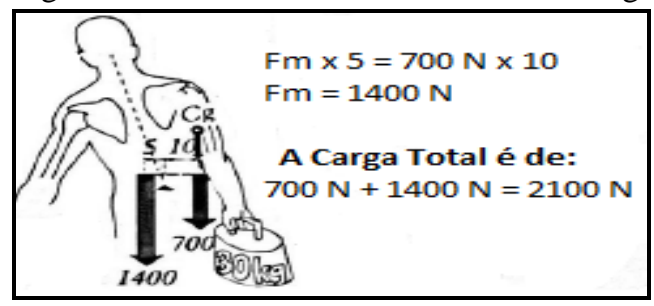

Fonte: Winher, 1986

Algumas posturas podem ser consideradas mais adequadas para cada tipo de atividade, porém existem alguns projetos inadequados de máquinas, assentos, etc., pois obrigam o trabalhador a atuar em uma postura inadequada, podendo provocar fortes dores no conjunto muscular solicitado para a conservação desta postura. Toda postura pode ocasionar a sobrecarga estática sobre os músculos e outros tecidos, podendo causar dores e desconforto, nenhuma postura é neutra, e nenhuma postura inadequada é adotada de forma condicional, mas é resultado de um conjunto de fatores. A tabela abaixo demonstra a localização das dores provocadas por posturas inadequadas e os riscos destas dores para o corpo humano (LIDA, 2005).

Tabela 1: Postura Inadequada e os Riscos de Dores

\begin{tabular}{|l|l|}
\hline Postura Inadequada & Riscos de Dores \\
\hline Em pé & Pés e Pernas (Varizes) \\
\hline Sentado se encosto & Músculos Extensores do Dorso \\
\hline Assento Muito Alto & Parte Inferior das pernas, joelho e pés \\
\hline
\end{tabular}




\begin{tabular}{|l|l|}
\hline Assento muito Baixo & Dorso e Pescoço \\
\hline Braços Esticados & Ombros e Braços \\
\hline Pegas Inadequadas em ferramentas & Antebraço \\
\hline Punhos em posições não-neutras & Punhos \\
\hline Rotações do Corpo & Coluna Vertebral \\
\hline Ângulos Inadequados assento/encosto & Músculos Dorsais \\
\hline Superfície muito baixa ou muito alta & Coluna Vertebral, cintura escapular \\
\hline
\end{tabular}

Fonte: LIDA, 2005

Mussashi (2004) faz uma grande comparação entre a ergonomia e o treinamento dos guerreiros Ninjas no período do Japão Imperial, onde ele comenta que o guerreiro deve ter uma boa base nos pés e no quadril, desta forma proporcionando movimentos rápidos e seguros, os movimentos dos braços de defesa e ataque devem ser curtos, pequenos, rápidos e precisos para que o guerreiro seja eficaz na sua batalha, mas que não fique cansado após concluir sua jornada.

Quando levantamos uma carga afastada do centro de gravidade, aumenta a pressão sobre os discos e vértebras da coluna na região lombar o que pode ter um grande potencial de lesão. Pesos acima de $4 \mathrm{Kg}$ são considerados elevados para manipulação, mas a utilização de força de forma rápida pode também provocar danos ao tecido muscular. (RODRIGUES, 2011).

Para realizar atividades físicas, nosso corpo atua com diversos tipos de alavancas, tendo em vista que apresentam grandes desvantagens biomecânicas, o que pode ampliar os riscos das articulações do ombro e principalmente do cotovelo. Para Rodrigues (2011). A avaliação da nocividade do fator forças em nosso organismo depende:

Da posição do objeto a ser utilizado proporcional ao corpo;

Do angulo e tamanho dos braços na realização da alavanca;

Do tempo e do tipo de contração;

Da freqüência na realização dos movimentos;

Da forma da ferramenta ou do objeto a ser trabalhado;

Do uso de luvas ou de ferramentas com vibratórias;

Das posturas e pegas.

\subsection{Lesão do Esforço Repetitivo (LER) / Doença Osteomuscular relacionados ao Trabalho (DORT)}

A ocorrência de LER/DORT vem crescendo de maneira temerosa, a expansão desta síndrome apresenta características de uma verdadeira epidemia, mesmo quando nos referimos 
apenas aos dados oficiais da previdência social de pessoas com vinculo empregatício regidas pela CLT, não sendo registradas as ocorrências de pessoas autônomas (NETO, 2010).

A coluna vertebral do ser humano é considerado um dos pontos mais fracos do organismo, como é uma peça delicada e importante para a locomoção do ser humano, esta sujeito a inúmeras deformações, que podem ser de causas congênitas (nascimento) ou adquiridas durante algum momento da vida, podemos, abordar a má postura no trabalho, provocados pelo esforço na execução da atividade, a repetição de movimentos, infecções entre outras (LIDA, 2005).

O primeiro sinal de alerta fica evidente através da fadiga muscular onde apresenta sinais como redução de capacidade muscular dentre outras. Nos casos mais críticos pode ocorrer dor severa localizada, gerando inclusive afastamento temporário ou permanente (LIDA, 2005).

As lesões ocupacionais prejudicam a saúde física e mental, proporcionando uma sensível redução na sua capacidade funcional, interferindo diretamente na produtividade e resultando na queda da qualidade de vida do trabalhador. Para (Saad, 2008), são cinco motivos aos quais os DORT têm aumentado em todo mundo nas ultimas décadas:

Pelo desequilíbrio entre as metas e a possibilidade de cumprimento do trabalho;

Pela quase total anulação dos mecanismos de regulamentação;

Pelo trabalho cada vez mais complexo realizado pelos trabalhadores;

Pela realidade social que favorece as lesões;

Pela intensidade dos fatores biomecânicos da tarefa.

A intenção de prevenir as LER/DORT, envolve todos, sem exceção, sendo indispensável à informação sobre os elementos da situação de trabalho, incluindo formas de identificação dos fatores de riscos de doenças osteomusculares, a avaliação de risco, os processos de gestão e as formas de prevenção destes (RODRIGUES, 2011).

\subsection{Trabalho Muscular}

A utilização do trabalho muscular pode ser dividida em dois grupos: O trabalho muscular estático é aquele que não possui movimentos articulares, assim não produz contrações isométricas, O trabalho muscular dinâmico caracteriza-se pela alternância de contração e extensão, funcionando como uma bomba hidráulica, ativando a circulação, porém o trabalho muscular dinâmico é 
repetitivo, sem analise e sem ferramentas adequadas podendo ser extremamente desgastante à saúde quando realizado por um longo período (LIDA, 2005).

Para Lida (2005), o sistema muscular demanda de um equilíbrio na quantidade de oxigênio, fornecido pelo corpo ao realizar uma atividade física. Uma recomendação, antes da realização de qualquer atividade física de maior intensidade consiste na realização de um pré-aquecimento muscular que dever ser realizado com uma duração aproximada de 3 minutos, reduzindo a probabilidade de haver um desequilíbrio na musculatura do corpo.

\subsubsection{Levantamento e manuseio de Cargas}

Muitos traumas musculares ocorrem no manuseio de cargas. Muitos traumas ocorrem devido à variação das capacidades físicas, treinamentos insuficientes substituição sem uma previa analise das tarefas dos trabalhadores homens realizados por mulheres (LIDA, 2005).

Para a Suíça (2004), após um estudo sobre ergonomia a OIT, fez algumas sugestões aos quais os trabalhadores devem realizar movimentações que não prejudiquem a sua estrutura musculoesquelética, conforme sugerido abaixo:

Ao levantar cargas, mantenha-a próximo ao corpo;

Levante-a com as duas mãos, mantenha a simetria do corpo e em posição vertical;

Mantenha sempre a carga o mais próximo possível do corpo;

Ao levantar a carga mantenha o tronco reto, agachando e Levantando;

Evite manipular materiais pesados em posturas prejudiciais;

Para levantar e transportar cargas pesadas utilize sempre que possível, gruas, elevadores, carretilhas, elevadores moveis ou dispositivos similares;

Solicite ajuda de outra pessoa para manipular materiais pesados e/ou volumosos.

Os efeitos da carga sobre o trabalhador são inúmeros. Muitas posturas exigem torções de tronco, o efeito é o tensionamento dos discos existentes entre as vértebras, a carga assimétrica também exige das articulações e músculos posicionados nos dois lados da coluna, posturas prolongadas e movimentos repetitivos por tempo prolongado, são condições que podem causar lesões localizadas provocadas principalmente pela fadiga muscular (AGAHNEJAD, 2014).

A torção do tronco é lesiva para as estruturas da coluna vertebral e tem efeito cumulativo, tanto no sentido de causa como de agravar uma ampla gama de distúrbios (SAAD, 2008).

Quando o trabalhador permanece em pé por períodos longos, utiliza todos os músculos do corpo. Com base nestes pontos é verificado que é altamente recomendável um local de trabalho 
onde o trabalhador possa alternar o seu trabalho em um período sentado e outro em pé (DUL; WENERMEEESTER, 2014).

Lida (2005), demonstra os princípios de economia de movimentos, onde são apresentados os pontos onde devemos procurar nos atentar ao corpo e assim projetar um posto de trabalho ideal e que venha a gerar pouco ou nenhum impacto ao operador e apresenta os pontos que causam influencia sobre o uso do Corpo Humano:

- $\quad$ As mãos devem iniciar e concluir os movimentos ao mesmo instante.

- $\quad$ As mãos não devem ficar paradas ao mesmo tempo.

- $\quad$ Os Braços devem mover-se em direções opostas e na mesma proporção.

- Deve-se utilizar movimentos manuais simples.

- Deve-se usar os movimentos (massa x velocidade) a favor do esforço muscular.

- $\quad$ Deve-se realizar movimentos suaves, evitando mudanças bruscas de direção.

- Movimentos terminando em anteparos são mais fáceis e precisos que os movimentos "controlados".

- $\quad$ O trabalho deve ser realizado em uma ordem compatível com o ritmo natural do corpo.

- $\quad$ Os acompanhamentos visuais devem ser reduzidos.

\subsection{Ferramentas Ergonômicas}

Os profissionais de ergonomia deparam com situações onde é necessário "quantificar" uma situação de trabalho analisada, onde podemos citar a quantificação do levantamento manual de cargas, que ainda nos dias de hoje é uma das maiores causas de disfunções músculo esqueléticas nos trabalhadores. (PEGATIN, 2008).

Para facilitar a necessidade de melhoria na movimentação e levantamento de cargas, foi criado a Equação de Levantamento Revisada do National Institute for Occupational Safety and Health (NIOSH), esta ferramenta é utilizada em diversos países. Sendo concebida para mensurar a demanda física e estimar o risco de lesões por sobrecarga e lombalgia (TEIXEIRA, 2011).

\subsubsection{Ferramentas de Aplicação NIOSH}


Esta ferramenta surgiu na década de 80, devido a grande preocupação do governo dos Estados Unidos quanto a preocupação com as doenças músculo-esquelético, vários pesquisadores reuniram-se para formular um método de prevenção solido sobre o assunto, priorizando a promoção da saúde e o combate as doenças do povo norte americano. Devendo contar com quatro critérios básicos, sendo:

Epidemiológico: Estudo das doenças provocado pelo movimento de levantamento de cargas, e assim, identificar a causa-efeito ou causa-doença e encontrar condições para reduzir e se possível eliminar possíveis doença ao trabalhador;

Psicológico: Estuda o comportamento em determinada situação, a obrigação em realizar algumas tarefas pode agravada problemas relativos à ergonomia no trabalho;

Biomecânico: Estuda a estrutura dos sistemas biológicos, envolvendo conceitos, métodos e leis da mecânica que influenciam o corpo humano;

Fisiológico: Estuda as funções do organismo, verificar o desgaste do operador e do organismo com relação à atividade física do local de trabalho. (LIDA, 2005)

A primeira fórmula foi criada em 1981, mas era limitada, tendo a altura vertical de $75 \mathrm{~cm}$ com relação ao chão e uma distância horizontal de $15 \mathrm{~cm}$ desde o ponto médio entre os joelhos. Em 1991 alguns valores foram revisados e outras variáveis foram acrescentadas, continuou a utilizar 75 cm para a altura vertical, a distância horizontal foi alterada de $15 \mathrm{~cm}$ para $25 \mathrm{~cm}$. Na equação inicial a constante de peso era $40 \mathrm{Kg}$, sendo alterado para $23 \mathrm{Kg}$, representando o peso máximo recomendável para a elevação de carga. A redução do peso ocorreu devido o aumento da distância horizontal de 15 para $25 \mathrm{~cm}$, esta equação tornou-se aceitável para 90\% das mulheres e dos Homens saudáveis. Em condições ideais, este peso resultaria em uma compressão discal menor que 3,4 Kn, tornando mais ampla a sua aplicação, considerando tarefas de elevação não simétrica, aplicável nas diversas condições de pega da carga e contemplar maior abrangência na freqüência das elevações e na duração do trabalho (WATERS, 1994).

\subsubsection{Condições para Aplicação}

Na aplicação dos cálculos NIOSH, são estipulados algumas condições para aplicação:

As elevações devem ser feitas de forma suave, sem movimentos Bruscos; 
Condições Térmicas e visuais adequadas;

Boas condições mecânicas - piso sem obstruções e planos oferecendo boa aderência ao calçado.

Para este cálculo, alguns itens não são aplicáveis:

Em tarefas onde é utilizado elevações com apenas uma das mãos, na posição de sentado, agachado, ou em espaço confinado que obriguem uma postura desfavorável;

Não contemplam a elevação com objeto muito quente ou frio;

Coeficiente de fricção estático, de no mínimo, 0,4 das superfície de contato com o solo;

Não inclui circunstâncias inesperadas;

Atividades de abaixar e levantar pesos têm o mesmo potencial para causar lesões Lombares;

Condições ambientais desfavoráveis (temperatura fora dos padrões de 19 a $26^{0} \mathrm{C}$ e umidade relativa, entre 35 a $50 \%)$.

Não incluída tarefas que resultem elevações rápidas (>15 elev./min.) (WATERS, 1994)

Após vários estudos foi definido a seguinte fórmula:

LPR $=23 \times$ FDH $x$ FAV $x$ FDVP $x$ FFL $x$ FRLT $x$ FQPC

Segue os seguintes parâmetros:

LPR= Limite de Peso Recomendado;

$\mathbf{2 3}$ = Valor constante é definido e pode ser manuseado sem risco particular para o operador;

FDH= Fator de Distância Horizontal em Relação à Carga;

FAV= Fator de Altura Vertical em Relação ao Solo;

FRLT = Fator de Rotação Lateral do Tronco;

FFL= Fator Freqüência de Levantamento;

Pega de Carga= Definição (Ótima, Boa ou Ruim)

A avaliação da equação de Levantamento do método NIOSH, deve ter os dados verificados para que não haja diferença nos valores, pois os erros de medição de cada variável afeta o Limite de Peso Recomendado (LPR), de diferentes formas, onde um erro de diferença de $10 \mathrm{~cm}$ na distância horizontal pode significar um erro de $30 \%$ no LPR, porém um erro de $10 \mathrm{~cm}$ na distancia vertical, resulta em no máximo 3\% de erro no valor do LPR. Um erro de 10 graus na definição do ângulo de 
assimetria resulta em no máximo 3,2\% do LPR. Um erro na definição da duração pode afetar em até $40 \%$ do LPR. A qualidade da pega resulta em um erro máximo de 10\% do LPR (TEIXEIRA, 2011).

Temos o Índice de Levantamento (IL), que determina se a atividade apresenta risco de lesão músculo esquelética. Muitos imaginam que o coeficiente constante 23 da fórmula é o peso ideal, sendo ampla e erroneamente difundido, sendo o IL, que é obtido dividindo o peso da carga com o resultado do LPR. (SILVA, 2014).

Conforme Teixeira (2011) Calculado o LPR, em quilogramas para uma tarefa especifica, onde ela é comparada o (PC), Peso da Carga real levantada. Essa relação entre a carga levantada e o LPR, Limite de Peso Recomendado, fornece o Índice de Levantamento, IL, onde representa uma estimativa do estress físico associado a tarefas a ser avaliadas, como na equação abaixo:

$$
\mathrm{IL}=\mathrm{PC} / \mathrm{LPR}
$$

Tabela 2: Situações obtidas

\begin{tabular}{|l|l|l|}
\hline IL menor que 1,0 & Condição Segura & Chance mínima de Lesão; \\
\hline IL entre 1,0 e 2,0 & Condição Intermediária & Médio Risco de Lesão; \\
\hline IL acima de 2,0 & Condição Insegura & Alto Risco de Lesão. \\
\hline
\end{tabular}

Fonte: Waters, et al. 1994

\section{Método}

A metodologia aplicada define de forma descritiva, tendo como objetivo principal identificar as características, envolvendo a observação e análise, podendo ser classificada quanto a característica tendo como base fundamental o uso do estudo de caso (TRALDI, 2011).

\subsection{Procedimentos}

a) Embasamento Teórico:

- Extraída através da pesquisa bibliográfica;

- $\quad$ Análise comparativa de obras e teoria existente;

b) Estudo de Caso:

- Comparar teoria a prática em um estudo de um caso real; 
- Bibliográfica/Documental, sendo estudados livros, normas, artigos, leis etc. Sendo alicerce a abordagem da ergonomia e assim promover a quebra de paradigmas referentes à sua utilização.

Numa $2^{\text {a }}$ fase será exploratória/descritiva, abordará um estudo de caso e demonstrar de forma prática, ganhos ergonômicos obtidos para os operadores e redução de possíveis afastamentos ou acidentes permanentes.

\subsection{Metodologia}

Realizado em uma indústria, onde foi identificada uma grande ocorrência de reclamações dos operadores com relação a dores na região lombar.

O estudo baseou-se na movimentação de caixas de produto prontos e embalado, proporcionando a movimentação da mesa do operador para o carro de transporte, sendo realizada a cada 1,5 minutos totalizando 40 caixas/hora e cada caixa pesa $20 \mathrm{~kg}$.

Definido algumas etapas e assim identificado algumas melhorias, visando melhorar o LPR e a redução do IL, proporcionando maior conforto e menor desgaste ao operador, reduzindo a fadiga e, obtendo ganhos expressivos na sua produtividade.

\section{Resultados e Discussão}

Para a realização do trabalho e com um menor desgaste físico ao operador, reduzindo a fadiga, o absenteísmo e, em contrapartida, obtendo ganhos na sua produtividade. As medições de LPR. e IL foram realizadas com base, primeiramente, na origem inicial da carga, ou seja, no ponto onde o trabalhador pega a caixa, definido como origem e posteriormente a medição do destino, com base na distância de movimentação da carga até o ponto de repouso da caixa, sendo obtido os pontos médios da atividade, assim como o valores do índice de Levantamento (IL).

$\mathrm{Na}$ atividade em questão, foram definidas as atividades em 3 etapas, onde foram verificadas as atividades para melhorias, sendo elas apresentadas na figura 7 :

1- Realizar a identificação do LPR e IL na condição atual, ou seja, como o operador trabalha;

2- Iniciado o revezamento a cada hora de trabalho, alternando as atividades e melhorando o distanciamento de pega da caixa no sentido horizontal.

3- Utilizar um carrinho plataforma reduzindo a movimentação do tronco na posição vertical. 
Figura 7: Graficos LPR e IL Origem e Destino
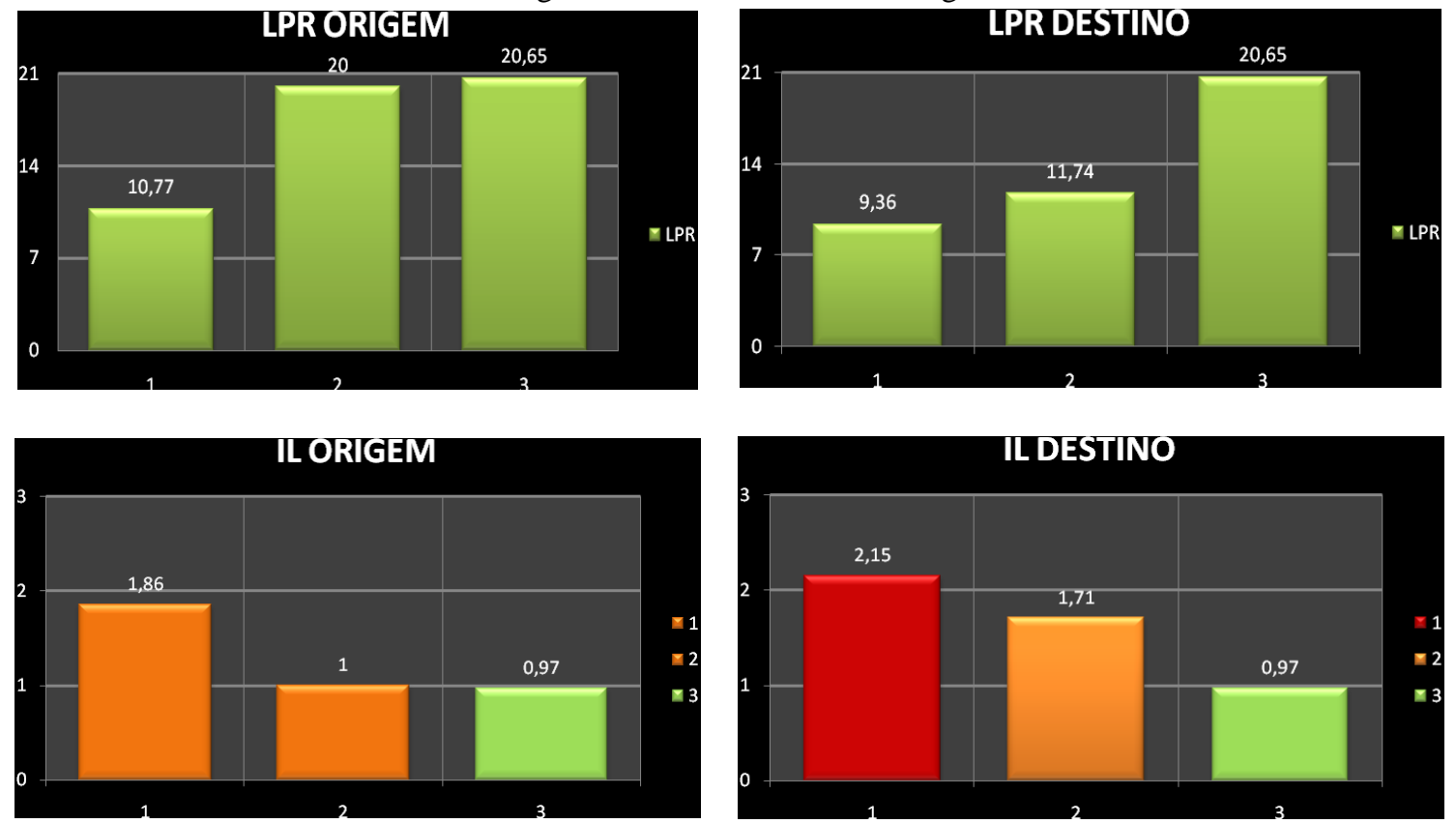

Fonte: Autor

Após verificar e realização de todas as etapas programadas chegou-se as seguintes conclusões:

A empresa obteve melhorias significativas nas atividades dos trabalhadores.

Redução dos índices que apresentam as possibilidades de lesão, saindo de uma alta situação de lesão e chegando a uma condição mínima de lesão.

Quebra de paradigmas, pois muitos engenheiros, trabalhadores e empresários, acreditam que a única solução para melhoria ergonomia é apenas o revezamento das atividades de trabalho.

Após a verificação o LPR e o IL, foi realizado um comparativo em termos de melhorias e os ganhos em termos percentuais, tanto na origem quanto no destino, chegando valores demonstrados na Figura 8:

Figura 8: Gráficos de Porcentagem do LPR e IL da Origem e Destino
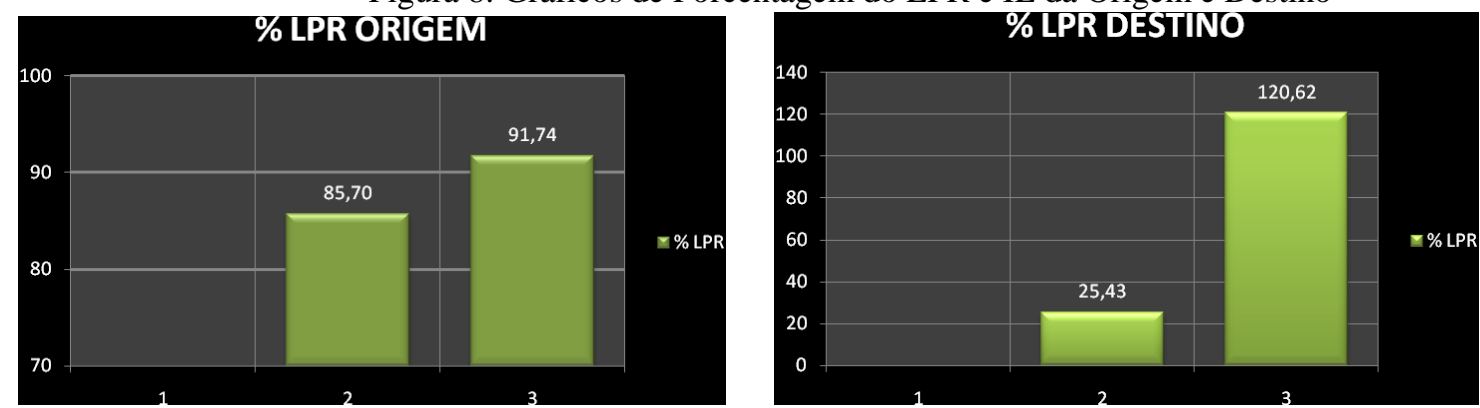

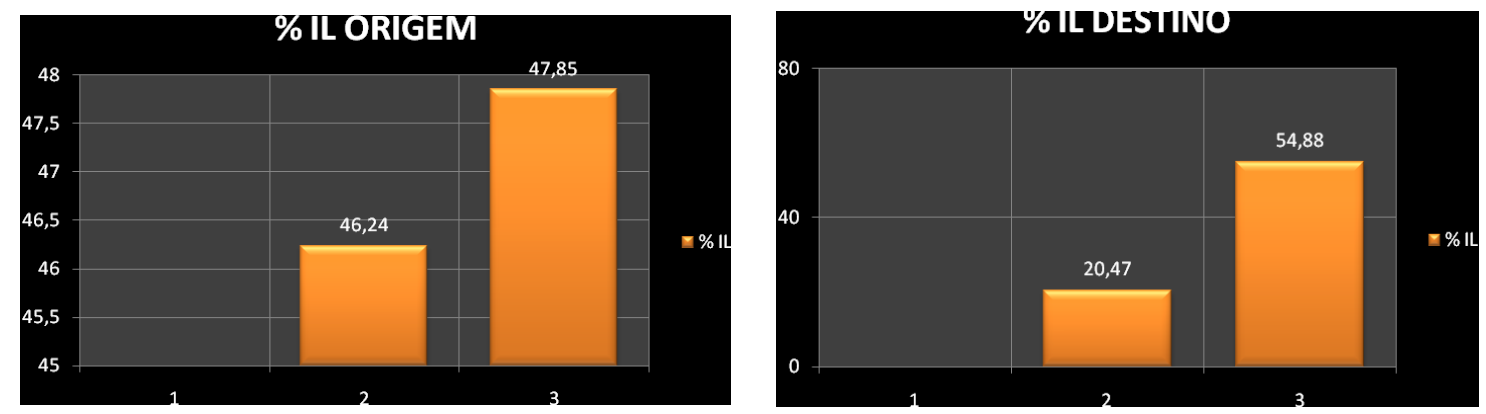

Fonte: Autor

\title{
5 Conclusão
}

Este trabalho apresentou a utilização do cálculo da equação elevação revisado do NIOSH, os ganhos são diretamente proporcional tanto para os trabalhadores quanto para os empregadores.

Para os trabalhadores apresenta a redução da fadiga do trabalho, reduzindo de forma substancial o stress no trabalho e a sobrecarga para a realização da atividade em questão.

Para o empregador apresenta ganhos significativos, já que o trabalhador terá uma redução na possibilidade de ocorrer algum tipo de trauma ou lesão e conseqüentemente, redução de faltas e afastamento no trabalho, indiretamente ocorrerá ganhos de produtividade, um melhor planejamento do controle da produtividade e da entrega dos produtos prontos para o cliente.

Para os órgãos governamentais são obtidos ganhos, pois serão reduzidos os afastamentos e os gastos com despesas para tratamentos e indenizações por sequelas decorrentes de locais de trabalho mal planejado.

Este cálculo poderia ser difundido em todas as empresas, desde as micro até as multinacionais, passando pelos órgãos públicos, porém ele é aplicado apenas em grandes empresas ou multinacionais, mas se fosse melhor divulgado os seus benefícios, proporcionariam ganhos expressivos para toda a sociedade.

\begin{abstract}
The postures are factors that influence bone structure of people, this study shows the need for a good posture, for the development of an activity come from ancient times and comes to the present day examples of improvements referenced Bernardino Ramazzini, the first to write about occupational diseases, their consequences for the organism, showing proper tools for each activity, generating productivity gains, with less impact to the health, safety for the human body.

The structure of the spine and the impact when we get up and we move objects weighing over $4 \mathrm{~kg}$ is already considered high for handling, may cause damage to muscle tissue, has an identified tool as Equation Survey Revised National Institute for Occupational Safety and Health (NIOSH), created in the 80 s and revised 90, and aims to identify epidemiological criteria, psychological,
\end{abstract}


biomechanical and physiological and find conditions to identify the Recommended Weight Limit (LPR) for activity and thus identify a Survey Index (IL) which is found with the load sharing by LPR, reaching a value that defines the risk of injury to the worker. It presents a real application, the initial activity, its risks, improvements and the increase in the weight limit to be busy and reduce the risk of injury by the employee. This work shows that in a good ergonomic analysis can move heavier loads with less risk, increasing productivity, reducing absenteeism and sick leave resulting from this reason.

Keywords: ergonomics; equation survey revised niosh; occupational diseases

\section{Referências}

AGAHNEJAD, Payman; LEITE, Jandecy Cabral; OLIVEIRA, Roberto Celio Limao de. Análise Edução Utilizando o Método NIOSH - Um Estudo de Caso no Polo Industrial de Manaus, INOVAE, São Paulo, v. 2, n. 2, p. 100-118, mai./ago., 2014.

BRASIL, MINISTÉRIO DA SAÚDE. Estatísticas de afastamento do trabalho. Visualizado em www.previdencia.gov.br/estatisticas/; dados retirados em 20/05/2016.

DUL Jan; WENERMEEESTER Bernard. Ergonomia Pratica. $3^{0}$ Edição Revista e Ampliada. São Paulo, Blucher , 2014.

LIDA, Itirio. Ergonomia Projeto e Produção. 2edição. São Paulo, Blucher, 2005

MACHADO, Luciano Ferreira. Desenvolvimento de um Programa Melhoria Ergonômica em uma Planta de Produção de Papel Higiênico. Dissertação de Mestrado, Universidade Candido Mendes, Campos dos Goytacazes, 2013.

MUSASHI, Miamoto. O Livro dos 5 Anéis. 6. Ed. São Paulo. Madras, 2004.

NETO Edgar Martins. Apostila de Ergonomia, São Paulo, Edgar, 2010.

PAULA, Adma Jussara Fonseca de; SEMENSATO, Cassiana Brosque; SILVA, José Carlos Plácido da; CARNEIRO, Luciane do Prado; PASCOARELLI, Luis Carlos. Engenheiros Precursores da Ergonomia e suas Contribuições, Vol. 02, N 04, São Paulo, Abril, 2010, visualizado em 22/06/2014, em www.ingepro.com.br

PEGATIN, Thiago. Ferramentas Manuais - Niosh. Artigo publicado em 01/04/2008, www.topergonomia.wordpress.com. Visualizado em 20/12/2014

PROTEÇÃO, Revista; Anuário Brasileiro de Proteção, Brasil, 2013, Visualizado no site http://www.protecao.com.br/materias/anuario_brasileiro_de_p_r_o_t_e_c_a_o_2013/estatisticas_de_acidentes_brasil/J9 y4Jj, em 22/03/2016

RAMAZZINI, Bernadino. As Doenças Ocupacionais, $4^{0}$ Edição, São Paulo, Fundacentro, 2016. Tradução Dr. Raimundo Estrêla.

RODRIGUES, Emilie Andrade, Avaliação da Exposição Ocupacional Ambiental e Biomecânica na Área das Carroçarias numa Fábrica da Indústria Automóvel, Dissertação mestrado, Universidade Técnica de Lisboa, Faculdade de Motricidade Humana, Portugal, 2011.

SAAD, Viviane Leão, ANÁLISE ERGONÔMICA DO TRABALHO DO PEDREIRO: O ASSENTAMENTO DE TIJOLOS, Dissertação de Mestrado, Universidade Tecnológica Federal do Paraná, Campus Ponta Grossa, Brasil, 2008.

SILVA, José Carlos Plácido da e PASCHOARELLI Luiz Carlos. Evolução Histórica da Ergonomia no Mundo e seus Pioneiros. 1 Edição. São Paulo, cultura acadêmica, 2010.

SILVA, Sergio Augusto Machado de Carvalho. Ergonomia, curso, Niosh. Visualizado no site www.drsergio.com.br em 27/07/2014. 
SUÍÇA, Organización Mundial de La Salud, Prevención de transtornos muscuesqueléticos em el lugar de trabajo. Ginebra, 2004.

TEIXEIRA, Eliana Remor. Lombalgia Relacionada ao Trabalho. Aplicação da Equação de Levantamento do NIOSH. 1edição. Curitiba, Juruá Editora, 2011.

TOLEDO Jr., I. Fides Bueno de. Tempos \& Métodos. $11^{0}$ Ed., São Paulo: Itys Fides, 2007.

TRALDI Maria C; DIAS Reinaldo. Monografia Passo a Passo. Edição Especial. Campinas, Alínea e Anhanguera (PLT), 2011.

WATERS, Thomas R; PUTZ-ANDERSON, Vern; GARG, Arun, Aplications manual for the Revised NIOSH Lifting Equation, Departmente of Helth and Human Services, Ohio, 1994.

WIRHED, Rolf, Atlas de Anatomia do Movimento, $1^{0}$ Edição, São Paulo, Manole, 1986.

\section{Dados dos Autores:}

Nome completo: Emerson da Silva Moreira

Filiação Institucional: Universidade de Taubaté

Departamento: Departamento de Engenharia Mecânica

Função ou cargo ocupado: Aluno de Mestrado Profissionalizante

Endereço Completo para correspondência: Av. Prefeito Moacyr Freire, 595 - Apartamento 3,

Granja Daniel, Taubaté, SP, CEP: 12060-801

Telefone para Contato: (12) 98131-0322

E-mail: emoreira2002@hotmail.com

Nome completo: Luiz Eduardo Nicolini do Patrocínio Nunes

Filiação Institucional: Universidade de Taubaté

Departamento: Departamento de Engenharia Mecânica

Função ou cargo ocupado: Professor Titular

Endereço Completo para correspondência: R. Daniel Danelli, s/n ${ }^{0}$, Jardim Morumby, Taubaté, SP, CEP: $12060-440$

Telefone para Contato: (12) 3625-4192

E-mail: lgpnunes@outlook.com

Submetido em: 21-08-2016

Aceito em: 31/12/2016 